\title{
ANÁLISE SOBRE A MONOCULTURA DE SOJA E O DESENVOLVIMENTO SUSTENTÁ VEL NA AMAZÔNIA COM BASE NA TEORIA DO DESENVOLVIMENTO ENDÓGENO
}

\author{
Rodrigo da Cruz de Araújo ${ }^{1}$
}

\begin{abstract}
Resumo
O trabalho apresenta uma análise teórica acerca do avanço da monocultura de soja na região Amazônica, abordando seus riscos e conflitos. O objetivo principal é analisar à luz da Teoria do Desenvolvimento Endógeno se tal atividade na Amazônia atende às premissas do desenvolvimento sustentável. Para isso, é apresentada e discutida a questão do avanço da monocultura de soja na região, expondo-se seus impactos negativos e os argumentos contrários àquela atividade. $\mathrm{O}$ trabalho traz como considerações finais reflexões acerca das características da sojicultura na Amazônia, as quais levam à conclusão de que, segundo o modelo atualmente praticado, foge da premissa do desenvolvimento endógeno, que teria como aspecto e condição a possibilidade de que os atores locais participem do processo e possam usufruir os rendimentos gerados como fruto de seus esforços.
\end{abstract}

Palavras-chave: Desenvolvimento sustentável, desenvolvimento endógeno, Amazônia, monocultura, soja

\begin{abstract}
The paper presents a theoretical analysis on the advancement of soy monocultures in the Amazon region, addressing its risks and conflicts. The main goal is to analyze by the Theory of Endogenous Development if such activity in the Amazon meets the premises of sustainable development. So, is presented and discussed the issue of advancement of soy monocultures in the region, exposing its negative impacts and main arguments against that activity. The paper presents final considerations as reflections of the characteristics of soybean production in the Amazon, which lead to the conclusion that, according to the model currently practiced, it flees the premise of endogenous development that would have as feature and condition the possibility that local actors participate in the process and enjoy the income generated as a result of their efforts.
\end{abstract}

Keywords: Sustainable development, endogenous development, Amazon, monoculture, soybean

\footnotetext{
${ }^{1}$ Engenheiro Civil pela UFPA. Mestre em Engenharia Civil (Geotecnia) pela PUC - Rio. Doutor em Desenvolvimento Sustentável pela UFPa. E-mail: rodrigocruzaraujo@gmail.com
}

Recebido em: 18/05/2014

Aceito em: 24/06/2014 


\section{1- INTRODUÇÃO}

O presente trabalho pretende fazer uma delimitação de um problema do Desenvolvimento Sustentável na Amazônia, com base nas categorias abordadas na teoria do Desenvolvimento Endógeno.

A definição de Desenvolvimento Sustentável costuma ser tradicionalmente resumida como aquele que consiga atender os seguintes requisitos: seja economicamente viável, socialmente justo e ambientalmente adequado.

Por sua vez, a teoria do Desenvolvimento Endógeno surge como contraposição aos modelos clássicos de crescimento, que levariam inevitavelmente a um estado estacionário da economia, situação que iria contra a premissa de que, para haver desenvolvimento real, é necessário que se estabeleça uma dinâmica de formação de produtividade crescente.

Assim, a teoria do Desenvolvimento Endógeno considera, em linhas gerais, que o desenvolvimento está relacionado à utilização, execução e valorização de recursos locais e à capacidade de controle do processo de acumulação, possibilitando a geração de rendimentos crescentes, por meio do uso de recursos disponíveis e da introdução de inovações, garantindo criação de riqueza e melhoria do bem-estar.

A implantação de monoculturas de soja na Amazônia vem se expandindo de maneira acelerada nos últimos anos, como reflexo do importante papel que tal commodity representa na balança de exportações nacional. Entretanto, tal avanço parece representar um risco ambiental, uma vez que sua expansão tornou-a uma das principais causas de desmatamento na região.

Para analisar melhor o papel desta atividade enquanto promotora de desenvolvimento regional parece então relevante que se faça uma abordagem mais detalhada sobre alguns temas, a começar pelos próprios conceitos de Desenvolvimento Endógeno e de Desenvolvimento Sustentável.

\section{2- DESENVOLVIMENTO ENDÓGENO}

Ao se pensar em analisar a possibilidade de desenvolvimento de certa região, é obrigatório ter em mente uma premissa: não há desenvolvimento sem formação de excedentes, ou seja, condições em que a quantidade de riqueza gerada pelo processo seja maior que a quantia gasta no mesmo. Logo, pensar em desenvolvimento implica obrigatoriamente em pensar na dinâmica de formação da produtividade crescente. 
Ocorre que, prevalecendo os modelos clássicos, que entendiam a produção como consequência apenas do trabalho e do capital, nos fluxos normais da economia a tendência seria de rendimentos decrescentes, estabelecendo-se assim um estado estacionário, o que significaria que ainda que se verificasse crescimento, o mesmo teria apenas caráter quantitativo.

Assim, surge a ideia de Desenvolvimento Endógeno, que consiste em endogeneizar uma série de variáveis anteriormente exógenas (tais como o capital humano, o meio-ambiente, etc.) de modo a gerar rendimentos crescentes.

Romer (1994) afirma que "crescimento econômico é um resultado endógeno de um sistema econômico, e não o resultado de forças que afetam a partir do exterior”.

Barquero (2001) afirma que "o desenvolvimento econômico ocorre em consequência da utilização do potencial e do excedente gerado localmente". Diz ainda que "para neutralizar as tendências ao estado estacionário, é preciso ativar os fatores determinantes dos processos de acumulação de capital, a saber, a criação e difusão de inovações no sistema produtivo, a organização flexível da produção, a geração de economias de aglomeração e de economias de diversidade nas cidades e o fortalecimento das instituições” (BARQUERO, 2001).

Amaral Filho (2001) considera que "um aspecto desse modelo está associado ao perfil e à estrutura do sistema produtivo local, ou seja, a um sistema com coerência interna, aderência ao local e sintonia com o movimento mundial dos fatores".

Garolfoli (1992) expõe que o desenvolvimento endógeno está relacionado à utilização, execução e valorização de recursos locais e à capacidade de controle do processo de acumulação.

Barquero (2001) corrobora com tal posição, afirmando que desenvolvimento endógeno ocorre "quando a comunidade local é capaz de utilizar o potencial de desenvolvimento e liderar o processo de mudança estrutural". Requer, ainda segundo o autor, "a existência de um sistema produtivo capaz de gerar rendimentos crescentes, mediante o uso de recursos disponíveis e a introdução de inovações, garantindo criação de riqueza e melhoria do bemestar".

Segundo Amaral Filho (2002), desenvolvimento endógeno pode ser entendido como um processo no qual o crescimento econômico induz a uma contínua ampliação da capacidade de geração e agregação de valor sobre a produção e também da capacidade de absorção da região na retenção do excedente econômico gerado na economia local e na atração de excedentes provenientes de outras regiões. 
Nesse sentido, alguns componentes como redes, inovação, instituições e espaço são importantes como fonte de rendimentos crescentes (BARQUERO, 2001).

\subsection{A Importância do Conhecimento e das Inovações}

Schumpeter (1982) introduz na discussão econômica a questão da importância das inovações. Para Schumpeter (1982), o desenvolvimento econômico viria pela mudança, que quebraria o estado estacionário. Entretanto, este autor só admite como "inovações” mudanças radicais, "desprezando" a importância de mudanças incrementais.

Nesse aspecto a visão de Schumpeter difere da teoria do desenvolvimento endógeno, para a qual mudanças incrementais tão importantes quanto as radicais. Essas inovações podem ser entendidas de maneira ampla, configurando-se de diversas formas, por exemplo, o desenvolvimento de novos produtos (ou introdução de novas qualidades), de novos métodos de produção, criação de novos mercados ou de novas formas de organização.

O conhecimento e a tecnologia são elementos de destaque nas teorias evolucionárias. Dosi e Nelson (1994) explicam que tal teoria tem o propósito de "explicar o movimento de algo ao longo do tempo ou explicar porque algo é o que é em um momento em termos de como chegou lá". Os mesmos autores reforçam que "os fundamentos da teoria repousam em processos de aprendizagem, envolvendo adaptações imperfeitas e descobertas por tentativa-eerro".

Cimoli e Dosi (1992) destacam que a tecnologia apresenta graus de:

- Oportunidade: variedade de possibilidades e/ou motivações que oferece,

- Cumulatividade: acumulação de conhecimento, ou seja, aprendizagem,

- Apropriabilidade: capacidade dos inovadores de interiorizar benefícios decorrentes do progresso técnico.

Os autores colocam que uma consequência fundamental dessas propriedades é a geração de assimetrias nas capacidades tecnológicas das empresas e dos países.

Garolfoli (1992) explica que o desenvolvimento endógeno apresenta alguns padrões, dentre os quais o controle sobre o processo de inovação, ou seja, a capacidade de interiorização e assimilação da inovação tecnológica ou organizacional, ou ainda de introduzir inovação diretamente. Conforme o autor resume, significa, portanto, capacidade de inovação a nível local.

Barquero (2001) considera que o desenvolvimento econômico e a dinâmica produtiva dependem das inovações e do conhecimento, uma vez que "a acumulação de capital se traduz 
por acumulação de tecnologia e de conhecimento", concluindo então que os processos de crescimento e mudança estrutural decorrem de inovações no sistema produtivo.

A “ideia geral", então, é que as inovações e o conhecimento provocam aumento de conhecimento tecnológico de qualquer tipo de sistema produtivo e, por isso, criam economias externas às empresas o que, por sua vez, provoca benefícios generalizados.

\subsection{A Importância das Redes e da Cooperação:}

Robertson e Langlois (1995) expõem que autores como Piore, Zeitlin e Sabel consideram que os grandes conglomerados não seriam necessários, sequer desejáveis. Segundo eles, aglomerações de pequenas firmas também gerariam elevados padrões de desenvolvimento. Assim, pequenas firmas teriam como vantagem a maior flexibilidade, sendo então mais adaptadas a gerar ou adotar inovações.

Robertson e Langlois (1995) colocam ainda que, por outro lado, outros autores, como Lazonick, têm posição inversa argumentando que apenas as grandes empresas teriam os benefícios da economia de escala, quais sejam: a possibilidade de produzir produtos melhores e mais baratos.

A crítica que se faz é que as opiniões contrárias usam exemplos distintos para analisar coisas distintas, de modo que ambas estariam certas "em parte": alguns setores (como o automobilístico, por exemplo) exigem de fato a constituição de grandes empresas; porém outros setores podem prescindir da economia de escala, "permitindo" o sucesso das firmas pequenas.

Além disso, outro argumento apresentado é que certos setores atingem nível ótimo e economia de escala sem implicar na necessidade de uma empresa "grande" (em termos de número de empregados, área física, etc).

Portanto, não haveria regra sobre "o que é melhor": ambas as opções podem ser adequadas e viáveis dependendo do contexto. A questão não reside na fonte de recursos, no tamanho das empresas, ou no tipo de cooperação (horizontal ou vertical), mas sim na possibilidade de que a população local retenha rendimentos a partir de seus esforços.

Garolfoli (1992) indica que existência de (e a capacidade de implementar as) redes produtivas e as ligações entre empresas locais é um padrão do desenvolvimento endógeno.

Amaral Filho (2001) expõe que esses novos modelos de desenvolvimento "estão identificados com as ações descentralizadas das empresas e das instituições públicas, o que implica um forte processo de reciprocidade entre eles, numa relação de concorrência e de cooperação entre as empresas". 
Barquero (2001) corrobora com essa posição, dizendo ainda que é a organização do entorno, no qual se estabelecem as relações entre as empresas, provedores e clientes que irá condicionar a produtividade e competitividade das economias locais.

As relações e interações estabelecidas entre as empresas permitem que as mesmas atinjam condições de economia de escala, provocando, portanto, vantagens que tendem a promover o desenvolvimento local.

Ainda, uma rede de empresas locais conduz à formação de diversos mercados internos, com maior facilidade de trocas (seja de produtos, serviços ou informações). Por fim, a atuação em redes tem ainda outra vantagem que é a de reduzir os custos de transação entre as envolvidas.

\subsection{A Importância das Instituições}

Enquanto para a teoria neoclássica o preço dependeria apenas da oferta e demanda, uma nova abordagem, denominada Economia Institucionalista, passa a analisar a firma incorporando também os custos que a produção e a venda representam. Desta forma, os custos de transação, antes sequer considerados, podem até mesmo ser mais significativos que os de produção.

Assim, autores como Coase, Williamson, Hodgson e North abordam a importância das instituições dentro da economia.

Os dois primeiros fazem parte do que se pode considerar "novos institucionalistas", aproximando-se do direito e baseando-se na racionalidade limitada. Coase (1988) centra-se mais na firma, nas transações, nos contratos e no mercado, procurando compreender o papel que tais elementos terão sobre os custos de transação. Williamson (1989) sofre influência de Coase, mas se debruça mais sobre a análise dos aspectos comportamentais das firmas, tais como o oportunismo dos agentes e a incerteza.

Assim, os custos de transação serão tanto maiores quanto forem as incertezas. Desta forma, para as grandes empresas tais custos são menores. Já para pequenas empresas, a operação em redes provocaria a redução dos mesmos.

É importante ressaltar que, ao se falar de “instituições", não se está falando obrigatoriamente daquelas formais, mas também de ideias e valores. Mudanças institucionais visando o desenvolvimento podem e devem ser buscadas. No passado, instituições não formais costumavam ser suficientes para conduzir os negócios; entretanto, hoje em dia na maioria das vezes há necessidade de medidas formais. 
Para North (1990) a questão central é a incerteza, que faz parte do processo econômico. Nesse contexto, as instituições entram como forma de minimizar os custos de transação. Existem diversos tipos de custos de transação: custos de measurement (desconhecimento da qualidade real e completa do produto) e enforcement (relacionado a transações complexas que requerem um tipo de proteção). Assim, North demonstra a dificuldade gerada pelas incertezas, que acarreta em aumento dos custos de produção. Dessa forma, o autor conduz ao entendimento da importância das instituições como meio para redução dos custos de transação.

Galípolo et al (2005), analisando possíveis influências de Marx sobre o pensamento de North, indica também algumas de suas diferenças fundamentais: enquanto Marx aponta o conflito de classes como motor do desenvolvimento, para North o desenvolvimento não se dá devido àquela contradição, mas pela inovação das instituições.

Então, conforme já mencionado, quando há assimetria nos contratos, elevam-se os custos de transação. A quebra de assimetria, por outro lado, deve levar a mudanças no comportamento oportunista e com isso, redução dos custos de transação.

Uma maneira de se promover essa quebra de assimetria nos contratos, por exemplo, é pela ação comunicativa: se os atores têm mesmo conhecimento, um não pode "levar vantagem" sobre o outro, gerando, portanto, contratos simétricos. Isso promove a cooperação entre os atores, levando a um resultado de soma positiva.

Amaral filho (2001) coloca, então, que nessa nova concepção de desenvolvimento regional, observa-se que a interação entre os agentes assume posição de destaque, requerendo a presença de três elementos: (i) construção da confiança; (ii) criação de bases concretas capazes de permitir a montagem de redes de comunicação, e (iii) proximidade organizacional.

Assim, um sistema institucional evoluído e complexo pode ajudar na promoção do desenvolvimento ao estruturar o entorno, estimulando a cooperação, inovação e aprendizagem em uma região. Barquero (2001) resume esse mecanismo dizendo que o fortalecimento das instituições reduz os custos de transação e de produção, aumentando a confiança entre os atores e com isso fortalecendo as redes de cooperação entre os mesmos e incentivando a aprendizagem e interação.

\subsection{A Importância do Espaço:}

Em relação ao espaço, deve-se observar que o mesmo pode ser entendido sob duas óticas: como distância em si, e como "qualidade". 
No primeiro caso, como distância propriamente, o espaço torna-se um fator definidor da opção entre "aglomerar" ou "deslocar" e introduz, dessa forma, tal variável na busca de produtividade crescente (ou seja, endogeneiza-a).

O espaço também pode ser visto por sua "qualidade", modo pelo qual pode entrar na questão de duas formas: pela distinção entre setores com raízes e sem raízes, o que faz que um ator se estabeleça ou não em um espaço específico; e pela possibilidade de contribuir para os rendimentos crescentes. Nesse último caso, a ideia é que setores sem raízes têm grande poder de crescimento com rendimentos crescentes, enquanto os setores com raízes têm limitação de crescimento dada pela própria natureza, apresentando então taxas decrescentes de rendimento.

O desafio do Desenvolvimento Sustentável é desenvolver formas que permitam que setores com raízes cresçam com rendimentos crescentes.

\section{3 - DESENVOLVIMENTO SUSTENTÁ VEL}

O que é desenvolvimento sustentável? Se analisado o conceito clássico adotado, percebe-se que apresenta enunciado com conteúdo profundo e complexo. Ribeiro (2002) considera que "o conceito de desenvolvimento sustentável é provavelmente o mais amplo, complexo e difundido já criado pela humanidade".

Sachs (1993) e Maimon (1996) definem desenvolvimento sustentável de maneira parecida, a qual pode ser resumida como uma busca da eficiência econômica, justiça social harmonia ambiental.

Costa (1998), diz que o enunciado largamente utilizado de "eficiência econômica, equidade social e prudência ecológica" é um ideário, pois na realidade do mundo moderno nenhuma situação seria descrita por tal conceito. Entretanto, ressalta que esse ideal de sustentabilidade "corresponde às necessidade estratégicas delineadas por manifestações concretas de insustentabilidade", devendo essa sim ser descrita e compreendida para averiguar seus mecanismos e combatê-los.

Alier \& Jusmet (2001) ressaltam que não se deve confundir extração com verdadeira produção sustentável, exemplificando tal confusão por meio da inadequabilidade de expressões como "produção de petróleo"; reforçando ainda a importância de se ter uma distinção clara entre recursos renováveis e não renováveis.

Os mesmos autores defendem então um entendimento do problema segundo a Economia Ecológica, a qual busca compreender a economia como um sistema aberto à entrada de energia e matéria e à saída de resíduos (visão diferente da economia neoclássica, 
que via a economia como um sistema fechado entre produtores e consumidores) e tem como objeto de estudo "a (in)sustentabilidade ecológica da economia" (ALIER \& JUSMET, 2001).

É importante entender que o desenvolvimento não ocorre ao acaso, mas como resultado de uma trajetória construída a partir das decisões e ações tomadas. Assim, segundo Costa (2006) o ideário de desenvolvimento sustentável impõe algumas tarefas para as ciências da sociedade: recapitular sua compreensão sobre a trajetória de desenvolvimento; verificar o que produz risco de insustentabilidade; ampliar a compreensão sobre esses riscos e incorporálos nas reflexões; e construir mecanismos que minimizem os mesmos.

No que diz respeito aos problemas ambientais, alguns economistas consideram que os mesmos seriam apenas externalidades e que poderiam então ser corrigidos pela sua internalização na estrutura de custos e preços das empresas. Alier e Jusmet (2001) explicam que, de acordo com tal lógica, existem diversas propostas para resolver o problema das externalidades negativas, por exemplo: negociação Coasiana, Valor Equivalente x Valor Compesatório, Imposto Pigouviano.

Entretanto, outra corrente da economia se põe contrariamente àquela abordagem, tendo como um dos argumentos principais o fato de que tal visão considera que todo dano poderia ser compensado e/ou reconstituído, o que não estaria correto, pois algumas mudanças produzidas na natureza implicariam em uma perda de qualidade, transformando matéria de qualidade em matéria degradada e gerando aumento de entropia, o que em última análise significaria que seriam irreversíveis e levariam à insustentabilidade.

Costa (2006) sintetiza a contradição dizendo:

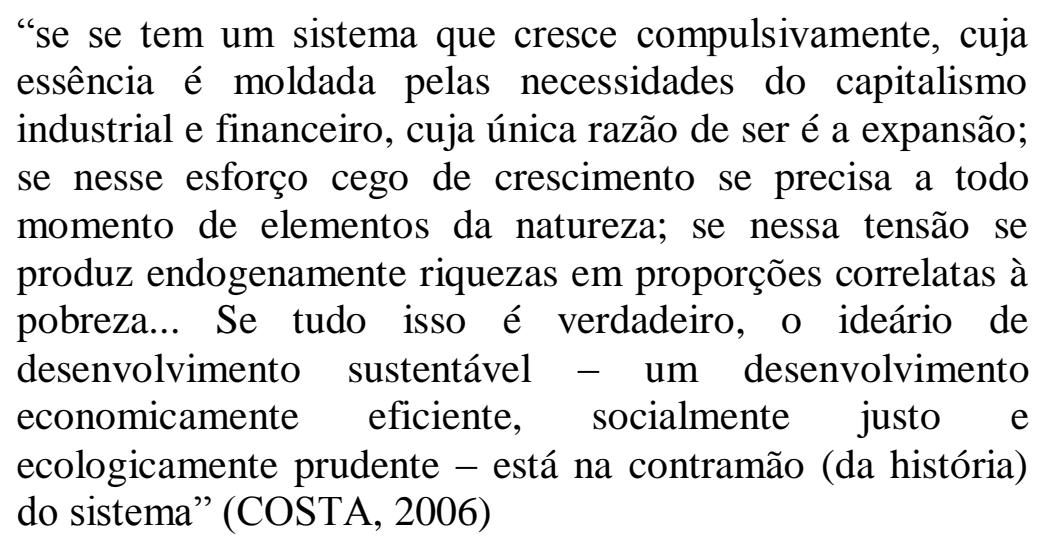

Como já mencionado anteriormente, a formação de excedente é condição necessária para o crescimento. A questão que surge é: só é possível obter crescimento (formação de excedente) com a destruição do meio ambiente? O trajeto histórico foi de aumentar a 
produtividade destruindo a natureza, mas outros tipos de uso são possíveis, criando riqueza sem tal destruição, ou seja, criando bases para o desenvolvimento futuro (COSTA, 2006).

Então, seria necessário introduzir a questão da sustentabilidade nos grandes debates relativos ao desenvolvimento (especialmente da Região Amazônica), não por meio de suas contradições polarizadas e "insolúveis", mas sim pelas suas possibilidades intermediárias de utilização da natureza.

Como já dito anteriormente, sem produtividade crescente do trabalho não é possível se pensar em desenvolvimento. Assim, para se produzir desenvolvimento sustentável é necessário investimentos elevados em ciência, que levaria à "criação" daqueles novos usos (que criassem riqueza sem destruição).

\section{4 - O CASO DA MONOCULTURA DE SOJA}

Exemplo de atividade que vem sendo conduzida pela "lógica" de crescimento com destruição da natureza e se apresenta como um problema de (in)sustentabilidade é a implantação de monoculturas na Amazônia (que não atendem às técnicas adequadas de manejo do solo).

A questão do avanço da monocultura de soja parece representar risco ambiental, especialmente na região amazônica. A expansão de tal atividade é hoje, provavelmente, uma das principais causas do crescimento dos desmatamentos na Amazônia.

Bickel (2004) descreve que "a expansão da soja no Brasil parece desenfreada". O autor faz essa colocação com base nos dados referentes à produção destes grãos no país. Segundo a Associação Brasileira das Indústrias de Óleos Vegetais (ABIOVE, 2005), em 2003 o Brasil era responsável por cerca de $26 \%$ da produção mundial de soja. Citando novamente Bickel (2004) “a soja é um dos principais produtos globalizados, sendo o produto agrícola mais comercializado a nível mundial”.

O complexo soja, de acordo com a Embrapa (2005), foi o principal produto de exportação do agronegócio brasileiro em 2004, sendo responsável por U\$10 bilhões da pauta de exportações do país, que no período foi de aproximadamente U\$96 bilhões.

Dados do IBGE (2009) apontam que a produção de soja no Brasil passou de cerca de 20 milhões de toneladas em 1990 para cerca de 23 milhões em 1996 e atingiu cerca de 51 milhões de toneladas em 2005. Quanto à produção na Amazônia Legal, a produção de soja passou de aproximadamente 3 milhões de toneladas em 1990 para cerca de 20 milhões em 
2005. Trata-se, portanto, de uma importantíssima atividade do ponto de vista econômico e que por isso mesmo desperta interesse geral.

Nesse contexto, o Governo do Pará (2005) adotou nos últimos anos uma política de incentivo à entrada e/ou expansão dessa cultura no estado. Segundo o Governo do Pará (2005), “com 6,2 milhões de hectares disponíveis para o plantio de soja, o Pará voltou-se para a cultura em 1995, quando teve início a criação do Pólo de Paragominas”. Ainda segundo a mesma fonte, "as áreas escolhidas foram as alteradas e as de cerrado, que no Pará correspondem à metade da área de soja plantada em todo o país".

Dados da Conab (2005) apontam que a soja no Pará iniciou-se em escala empresarial em 97/98 com 2,6 mil hectares e avançou de tal forma que no período 2004/2005 já ocupava cerca de 69 mil hectares. O Governo do Pará (2005) afirma ainda que pesquisa realizada nos dois pólos sojeiros pioneiros do estado (Paragominas e Redenção) “constatou a viabilidade da soja no Pará, ao apresentar uma produtividade média de 45 a 50 sacas $(60 \mathrm{~kg}$ ) por hectare, acima da média nacional, que é de 35 sacas por hectare". Os dados citados em relação à produtividade são confirmados pelos divulgados pela Conab (2005), que indica uma produtividade de $3000 \mathrm{~kg} / \mathrm{ha}$ no Pará contra uma média nacional de aproximadamente $2200 \mathrm{~kg} / \mathrm{ha}$.

O problema desse tipo de abordagem é que a mesma confere ao aspecto econômico um peso muito grande (se é que não se possa considerar que absoluto) e não parece tão criteriosa em relação a outros aspectos, especificamente aos sociais e ambientais. Entretanto, é cada vez mais difundido e aceito (o que realmente parece inquestionável) que o mundo precisa se preocupar com a sua sustentabilidade.

Diversos setores da sociedade têm demonstrado preocupação e contrariedade quanto ao avanço daquela atividade, podendo-se citar como exemplos os protestos da própria comunidade local, que conta com o apoio do Greenpeace.

De acordo com diversas pesquisas, a conversão de florestas em campos de soja tem sérios custos socioambientais, dentre os quais: os efeitos nocivos dos agrotóxicos no meioambiente e na saúde humana, a expulsão de sua terra das comunidades nativa e a erosão do solo com consequente assoreamento e poluição de mananciais.

\section{5- CONCLUSÕES}

Casos como da soja configuram exemplos práticos de situações nas quais a natureza impõe limitações. O setor usa o território como matéria-prima, a ser "descartada" quando esgotada suas limitações naturais. Trata a natureza como se fora um "input" industrial. Seus 
danos são diversos, complexos, ocorrendo problemas em "efeito dominó" (o desmatamento provoca erosão, que provoca assoreamento, que provoca...) e em grande parte, possivelmente irreversíveis. A perda de biodiversidade tão rica pode representar a eliminação de recursos com uso potencial futuro sequer conhecidos nos dias de hoje. Constitui-se, então, em uma situação em que seria difícil a "monetarização" dos mesmos como uma tentativa de repará-los simplesmente pela internalização nos custos e preços.

Ao mesmo tempo, do ponto de vista social, conforme já mencionado anteriormente, diversos autores apontam que a soja requer investimentos elevados, o que implica em uma nova organização social na qual os grandes empresários são favorecidos em detrimento do pequeno produtor, provocando a expulsão de comunidades locais, a concentração de terras e de renda, a desigualdade social, etc. Em outras palavras, a entrada de grandes produtores (como no caso da soja) tenderia a "desestabilizar" a organização e a dinâmica social até então estabelecidas, alijando a participação dos pequenos produtores locais, que não teriam condições de se manter atuantes em uma nova realidade que requereria altos investimentos.

Dessa forma, uma análise acerca do avanço da soja na Amazônia, de acordo com o exposto até aqui, leva à conclusão de que se trata de uma atividade que não atende ao entendimento de desenvolvimento como algo que em conjunto com a geração de riqueza também provoque o aumento da qualidade de vida dos envolvidos, gerando mercados em rede que operem com base na cooperação. Pelo contrário, a parcela de rendimentos gerados pela atividade que permanece no local é muito baixa. Ou seja, tal atividade foge da premissa do desenvolvimento endógeno, que teria como característica e condição a possibilidade de que os atores locais participem do processo e possam usufruir os rendimentos originados como fruto de seus esforços.

Enfim, é uma realidade nova se impondo sobre as culturas, tradições e organização que existiam anteriormente em certa localidade, que não gera redes de cooperação envolvendo os atores locais, não permite que os mesmos possam usufruir os ganhos gerados na região e usa o espaço de maneira destrutiva. Tudo isso é, portanto, altamente exógeno e só tende à insustentabilidade.

\section{REFERÊNCIAS BIBLIOGRÁFICAS}

ALIER, J.M. \& JUSMET, J.R. Economía ecológica y política abiental. Fondo de Cultura Económica, 2001. 
AMARAL FILHO, Jair do. A endogeinização no desenvolvimento econômico regional no local. Revista Planejamento e Políticas Públicas, IPEA - Instituto de Pesquisa Econômica Aplicada, Rio de Janeiro, n. 23, p. 261-286, junho 2001.

AMARAL FILHO, J. Desenvolvimento regional endógeno: (re)construção de um conceito, reformulação das estratégias. Revista Econômica do Nordeste, v. 26, n. 3, 2002.

BARQUERO, A. V. Desenvolvimento Endógeno em tempos de globalização. Tradução: Ricardo Brinco. Fundação de Economia e Estatística, 2001

BICKEL, U. Brasil: Expansão da Soja, Conflitos Sócio-Ecológicos e Segurança Alimentar. Dissertação de Mestrado em Agronomia Tropical, Universiadade de Bonn, Alemanha, 2004.

CIMOLO, M. \& DOSI, G. Tecnología y desarrollo.Algunas consideraciones sobre los recientes avances en la economía de la innovación. In: El Cambio Tecnologico Hacia el Nuevo Milenio, 1992.

COASE, R.H. The firm, the market, and the law. The University of Chicago Press, 1988.

COSTA, F.A. Ciência, Tecnologia e Sociedade na Amazônia: Questões para o Desenvolvimento. Belém: CEJUP, 1998.

COSTA, F.A. Teorias do Desenvolvimento e Estratégias do Desenvolvimento Sustentável. Texto Didático, 2006.

DOSI, G. \& NELSON, R.R. An introduction to evolutionary theories in economics. Journal Evolutionary Economics, 1994.

GALÍPOLO, G., GALA, P. E FERNANDES, D.A. Notas para uma avaliação da influência de Marx em Douglas North. Anais da Anpec XXXIII, 2005.

GAROFOLI, G. Endogenous Development and Southern Europe, Avebury, Aldershot, UK, 1992.

NORTH, D.C. Institutions, Institutional Change and Economic Performance. Cambridge University Press, 1990.

MAIMON, D. Passaporte Verde: Gestão Ambiental e competitividade. Rio de Janeiro: Qualitymark, 1996.

RIBEIRO, A. Modelo de Indicadores para Mensuração do Desenvolvimento Sustentável na Amazônia. Tese de Doutorado. Núcleo de Altos Estudos Amazônicos. Universidade Federal do Pará. Belém, 280p. , 2002.

ROBERTSON, P.L. \& LANGLOIS, R.N. Innovation, networks, and vertical integration. Research Policy, 1995.

ROMER, P.M., Origins of Endogenous Development. Journal of Economic Perspectives, vol.8, n.1, 1994. 
SACHS, I. Estratégias de transição para o século XXI: Desenvolvimento e meio ambiente. São Paulo: Nobel, 1993.

SCHUMPETER, J.A. Teoria do Desenvolvimento Econômico: uma investigação sobre lucros, capital, crédito, juro e o ciclo econômico. Trad. Maria Silvia Possas. Os Economistas, São Paulo: Abril Cultural, 1982.

WILLIAMSON, O.E. Las Instituciones Económicas del Capitalismo. Fondo de Cultura Económica, 1989.

\section{Sites Consultados:}

Associação Brasileira das Indústrias de Óleos Vegetais (ABIOVE): http://www.abiove.com.br/ (acessos em 03/07/2005 e 04/02/2010)

CONAB (Companhia Nacional de Abastecimento) : http://www.conab.gov.br/ (acesso em 03/07/2005)

Empresa Brasileira de Pesquisa Agropecuária: www.embrapa.gov.br (acesso em 07/08/2005)

Governo do Estado do Pará: http://www.cdpara.pa.gov.br/economia/agropec/soja.html (acesso em 03/07/2005)

IBGE (Instituto Brasileiro de Geografia e Estatística): http://www.ibge.gov.br/ (acesso em 05/11/2009) 